\title{
The effect of fiber laser parameters on microhardness and microstructure of duplex stainless steel
}

\author{
Ghusoon R. Mohammed ${ }^{1,2,}{ }^{*}, M$. Ishak ${ }^{1}, S$. N. Aqida ${ }^{1}$, and Hassan A. Abdulhadi ${ }^{1,2}$ \\ ${ }^{1}$ Faculty of Mechanical Engineering, University Malaysia Pahang, Pekan 26600, Pahang, Malaysia \\ ${ }^{2}$ Middle Technical University, Baghdad, Iraq
}

\begin{abstract}
An investigation was implement to study the influence of laser power, and speed of the welding on hardness, microstructure, and penetration of laser welding bead on plate duplex stainless steel, which is not exhibited so far. A fiber laser was selected for welding duplex stainless steel sheet with $2 \mathrm{~mm}$ thickness. Then, optical microscope (OM) was used in the morphologic observation of cross section, penetration depth, and bead width. Microhardness of the welded sheet was measured using Vickers hardness. Profiles of hardness and microstructure were utilized to discriminate welding line and to propose superior welding parameters. The experimental results displayed that, a good quality of duplex steel welds can be acquired when a suitable fiber laser welding parameters were selected. It was found that microhardness profiles showed a rise in the hardness of the weld and heat-affected zones as the solidification process proceeds rapidly. Additionally, the crystal solidification process induced by the fiber laser welding was schematically clarified and systematically exposed.
\end{abstract}

\section{Introduction}

Typically, duplex stainless steels is a grade of virtually an equal proportion of two phases austenite-ferrite. Duplex stainless steels offer a few favorable benefits. They consolidate the mechanical property and corrosion resistance points of interest of both the austenitic and the ferritic grades. The austenite conferring extensive corrosion resistance and strength while the ferrite giving impedance to chloride stress corrosion and toughness [1].

Various welding and joining techniques are adopted in products as well as structures. Among such, laser welding accelerates power saving, automation as well as systematization. Noted as a technology, it achieves high precision and quality, large flexibility and welding rates, used in various applications. Laser welding's heat source may be a LD (diode laser), YAG laser, LD pumped solid laser, disc and fiber laser, and CO2 laser (carbon dioxide gas laser) [2]. In recent years, a rapid growth has been existed in fiber laser application with the flexibility of fiber, resulting in high beam quality and efficiency by miniaturization, where it is used as a heat source with high power and power density. For instance, using a $10 \mathrm{k}$ fiber laser with high power, attaining a large beam quality of a few $\mathrm{mm}$ mrad is possible, with about $25 \%$ high efficiency, high compactness and about $1 \mathrm{MW} / \mathrm{mm}^{2}$ of power densification [3].

The duplex stainless steel has been explored to offer a composition of pitting and stress corrosion cracking resistance and strength, comparing with the 300 series austenitic

* Corresponding author: ghusoon_ridha@yahoo.com 
stainless steel [4]. Such particular properties have led to the various industrial application uses, such as oil and gas transmission lines, chemical process plant piping and marine environment structure[5,6]. Because welding is adopted extensively in such applications, it is critical for the good implementation of such materials of engineering to understand the factors affecting the ability of welding of duplex stainless steels.

In general, the balance ration of ferrite/austenite has a remarkable impact on the corrosion and mechanical properties $[7,8]$. The best property of such steels is realized while in the microstructure almost equal ferrite and austenite proportions exist (Fig.1). Within base metals, such phase balance is achieved through a proper combination of solution heat treatment and composition. Nevertheless, the balance control of austenite/ferrite in welds is not easy as among base metals [9-12].

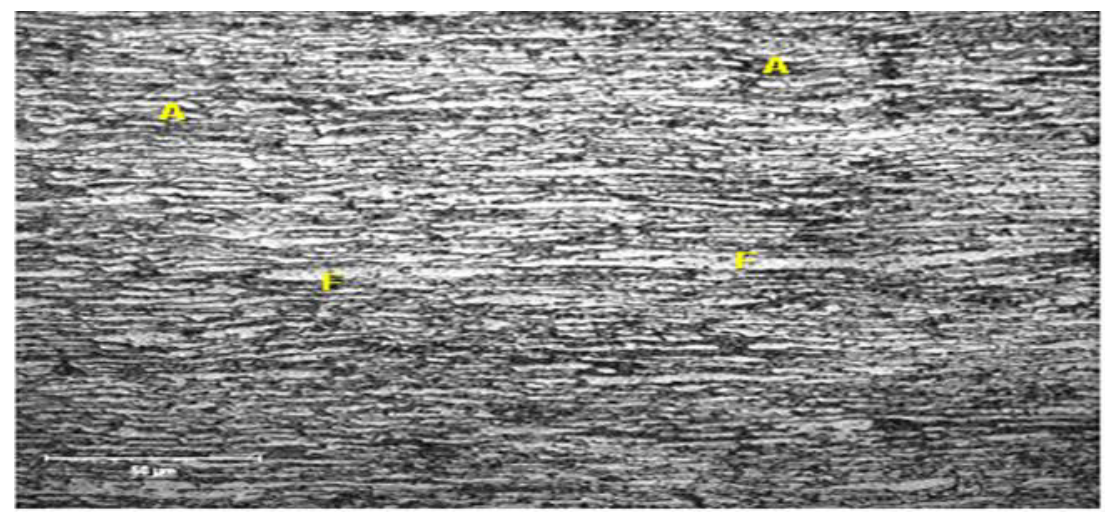

Fig. 1. The microstructure of duplex stainless steel base metal showing Ferrite (F) and Austenite (A) phases.

Previously, researches have proved that the microstructure of weld and heat affected zones is a function of the cooling rate of high temperature [13-15]. As a result, the austenite/ferrite balance within fusion zone is expected to be influenced by welding speed and laser power $[16,17]$. But the research region has got relatively few explorations, more efforts are needed for in-depth understanding of the influence of various laser welding parameters on duplex stainless steel properties. Presently, this research is about the effect laser beam parameters and its influence on fusion zone and microstructure of duplex steel welded.

Laser welding process provides a lot of good qualities on welded metal. However, the rapidity and perfection of the weld is a future problem. Currently, a lot of researchers focus on welding of cans, domestic equipment, aircrafts and cars [18-20]. Welding depth and shape are affirmed with the way that the energy of welding is used on the joint. The input energy of laser welding is under the control of the following parameters: Laser power, welding speed, keyhole shielding gas and focus spot size. In addition, the repetition of welding performance depends on the material preparation, joint fit-up and laser beam to joint alignment. All the above-mentioned parameters are the inputs to welding process which are controlling the output quality of the joint [21].

Stainless steels may be classified into the austenitic, duplex, martensitic and ferritic family. The duplex family provides a suitable blend of toughness, weldability and economy are frequently chosen where both corrosion and strength properties are essential [22]. DSSs are more, in fact, requesting than the grades of standard austenitic stainless steel, like type 316 and 304.

During welding, avoiding secondary phases and maintaining the good austenite and ferrite balance is important. Typically, laser welding is a process of a high cooling rate that 
is so far, causing a problem in the welding of duplex stainless steels. The fast cooling results in undesired alterations in the microstructure of the weld metal. That's considered in the case of welding duplex steel as laser welding of duplex stainless steels can be challenge exceptionally whether filler metal did not utilize [23]. Besides, further effort is needed for preferable comprehension the effectiveness of welding parameters (welding speed, laser power) on the forming of weld bead; the evolution of weld microstructure; the allocation of the essential alloying component; and from, the variance in microhardness crossed the weld. Thus, in the present paper, the impact of input power on weld joint shape, the progression in the microstructure, and alteration in the microhardness throughout weld regions will investigate.

\section{Experimental procedure}

In this research, the material adopted is SAF 2205 duplex stainless steel; 2mm plate thickness, which chemical composition is presented in Table 1. Bead on plate weld was achieved with fiber laser welding process in pulse wave mode with maximum output power of $2 \mathrm{~kW}$. Figure 2 shows the configuration of fiber laser welding joint.

The weld specimens were prepared with dimension $(75 \times 50 \times 2 \mathrm{~mm})$, and a fixture was used to prevent distortion. Table 2 show the parameters of fiber laser welding that used (P: Peak power, S: welding speed, Heat input: Q, Pd: Pulse duration, Df: defocusing). In addition, Argon was used as a shielding gas with a flow rate $201 / \mathrm{min}$.

After welding process, the samples were inspected and sectioned transverse to the direction of welding. The samples were prepared for the metallographic inspection using standard technology. The size and microstructure of fusion zone were inspected using optical microscope. Hardness was carried out for fiber laser welded having complete penetration.

After welding process, both macro-and microscopic examinations were carried out for cross sections taken from welded specimens. The welds were cut and prepared as metallographic samples to evaluate, the integrity of the weld beads. Microscopic examinations were carried to clarify the microstructure of WM, HAZ and BM including the extent of ferrite and austenite phases.

The specimens were prepared for such metallographic examination using standard grinding, polishing and etching techniques. Specimens were ground with emery paper ranging in fineness from 320 up to 1200 equivalent mesh, and then polished with alumina suspension. Finally, polished specimens were etched in a Modify Kalling's solution (5 mg $\mathrm{CuCl}_{2}, 100 \mathrm{ml}$ ethanol, $100 \mathrm{ml} \mathrm{HCl}$ ) then, cleaned using distilled water with and dried by air. Microhardness Vickers tester was implemented to measure the hardness by applying a standard load of $500 \mathrm{gf}$ for a time of $10 \mathrm{~s}$ as a dwell period.

Table 1. Chemical composition (wt. \%) of duplex stainless steel used.

\begin{tabular}{|c|c|c|c|c|c|c|c|c|c|}
\hline $\mathbf{C r}$ & $\mathbf{N i}$ & $\mathbf{M n}$ & $\mathbf{C}$ & $\mathbf{S i}$ & $\mathbf{P}$ & $\mathbf{S}$ & $\mathbf{M o}$ & $\mathbf{C u}$ & $\mathbf{N}$ \\
\hline 22.07 & 5.54 & 1.146 & 0.03 & 0.587 & 0.026 & 0.003 & 3.01 & 0.20 & 0.16 \\
\hline
\end{tabular}

Table 2. Process parameters of fiber laser welding.

\begin{tabular}{|c|c|c|c|c|}
\hline $\mathbf{P}(\mathbf{k W})$ & $\mathbf{S ~ ( m / \mathbf { m i n } )}$ & $\mathbf{P d}(\mathbf{m s})$ & $\mathbf{D f}(\mathbf{m m})$ & $\mathbf{Q}(\mathbf{J} / \mathbf{m m})$ \\
\hline $1,1.2,1.4,1.6$ & 0.16 & 4 & +2.5 & $240,288,336,384$ \\
\hline 1.4 & $0.08,0.09,0.11,0.16$ & 4 & +2.5 & 336 \\
\hline
\end{tabular}




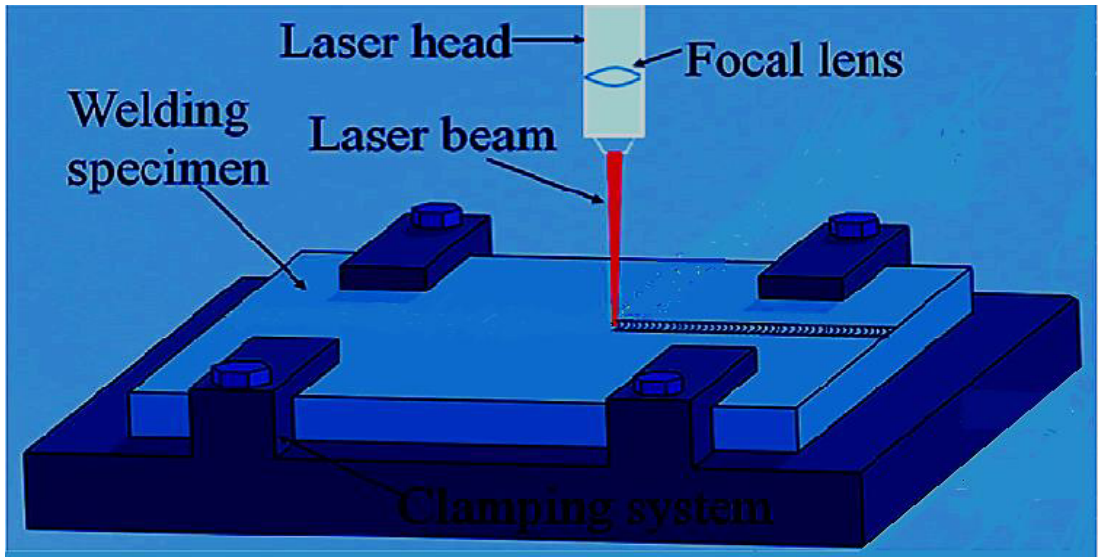

Fig. 2. Schematic of the laser welding configuration.

\section{Results and discussion}

\subsection{Influence of laser power}

The influence of laser power was explained with the welding speed of $0.11 \mathrm{~m} / \mathrm{min}$ and defocusing distances of $+2.5 \mathrm{~mm}$. In Fig. 3, the cross section of laser bead on plate welds was performed with a welding speed of $0.11 \mathrm{~m} / \mathrm{min}$. The characteristic of fiber laser welding is affected by numerous significant ingredient. These features are the penetration depth, width of the welded joint and the final appearance of the weld surface [24].
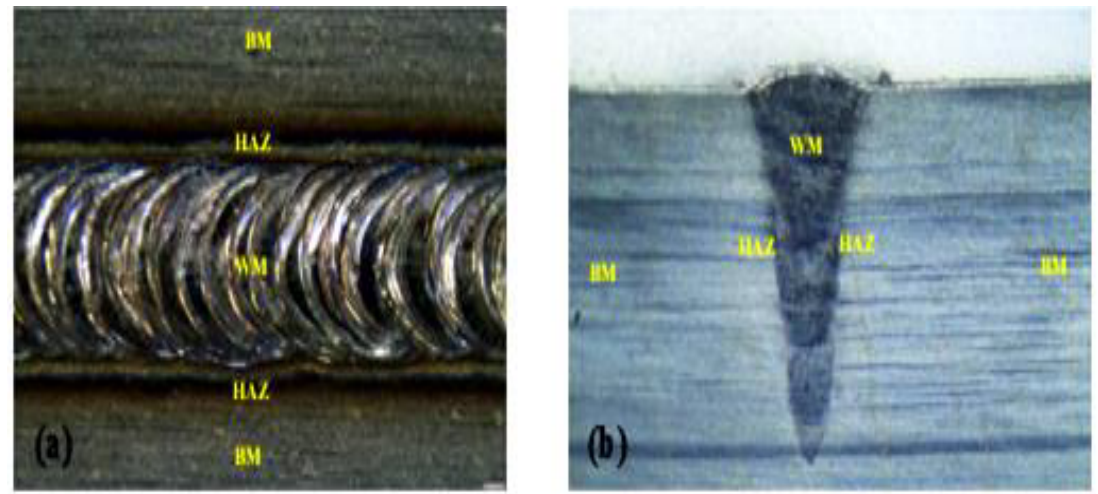

Fig. 3. Macrographs of the fiber laser welded present the various welding regions (a) the top surface appearance and (b) sectional appearance.

Fig.4(a-d) shows the surface of the fiber laser welds under different laser welding parameter compounds and the influence of fiber laser welds on the surface appearances under laser power of $1.4 \mathrm{KW}$ and speeds of $0.08,0.09,0.11,0.16 \mathrm{~m} / \mathrm{min}$ sequentially. The average results of the hardness are present in Table 3 for duplex steel 2205 at three value $(1.2,1.4,1.6 \mathrm{KW})$ of heat inputs. An improvement was noticed in the weld zone and HAZ Hardness of SAF 2205 with the increase of the energy from 288 to $384 \mathrm{~J} / \mathrm{mm}$. The profile of the Microhardness of different laser welding power across section of the bead on plate duplex stainless steel was illustrates in Fig.5. Additionally, it was found that, the relation between the peak power and the penetration was almost liner as can be notice in Fig.6. 

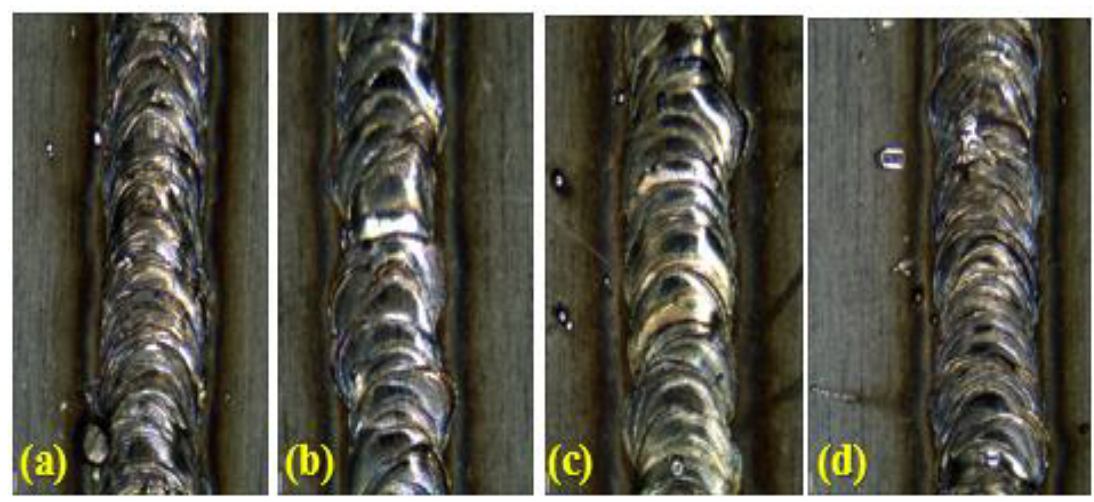

Fig. 4. The surface appearances of the fiber laser weld with laser power of $1.4 \mathrm{KW}$ and speeds of (a) $0.08 \mathrm{~m} / \mathrm{min}$, (b) $0.09 \mathrm{~m} / \mathrm{min}$, (c) $0.11 \mathrm{~m} / \mathrm{min}$, (d) $0.16 \mathrm{~m} / \mathrm{min}$.

Table 3. Hardness of different zones of bead on plate duplex stainless steel.

\begin{tabular}{|c|c|c|c|}
\hline Heat input (KW) & BM & HAZ & WM \\
\hline 1.2 & 266.1 & 274.1 & 313.9 \\
\hline 1.4 & 266.2 & 284.1 & 322.6 \\
\hline 1.6 & 267.4 & 290.3 & 329.6 \\
\hline
\end{tabular}

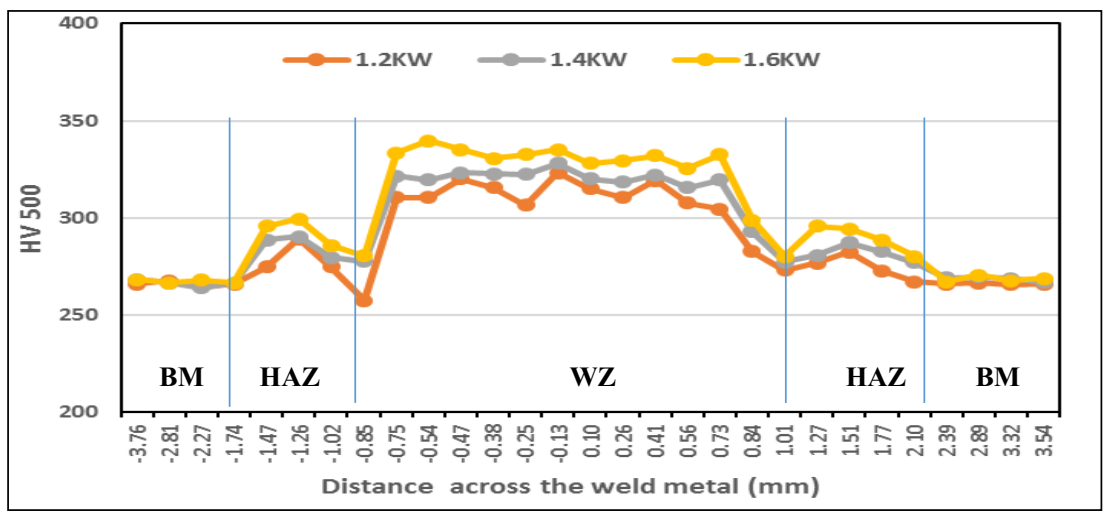

Fig. 5. Microhardness profile of different laser welding power across section of the bead on plate duplex stainless steel.

Results of different welding parameters are exhibited in (Fig.8). As to distinct sets of welding parameters, cross sections of the weld were examined. It was showed that appropriate weld bead profiles were accomplished with $0.11,0.16,0.08$ and $0.09 \mathrm{~m} / \mathrm{min}$ welding speed. On top of the weld metal area, at the speed of $0.16 \mathrm{~m} / \mathrm{min}$ the undercut was observed

\subsection{Influence of laser welding speed}

The speed of welding and laser power is the parameter determining the energy of weld $(\mathrm{J} / \mathrm{mm}$ of weld length) and as a consequence, the property, and shape of the weld. Considering the influence of welding speed on the quality of the weld, $0.09 \mathrm{~m} / \mathrm{min}$ was the chosen speed. No evidence of defects exists, like undercut or porosity. The weld width is about $0.75 \mathrm{~mm}$, and the HAZ width is about $0.1 \mathrm{~mm}$. The joint may be divided into 
numerous discrete metallurgical areas, the HAZ (heat affected zone), the BM (base metal) and the FZ (fusion zone) in the center. The zone of fusion includes grains that are coarse, columnar and dendritic, aligned in a perpendicular direction to the boundary of fusion zone.

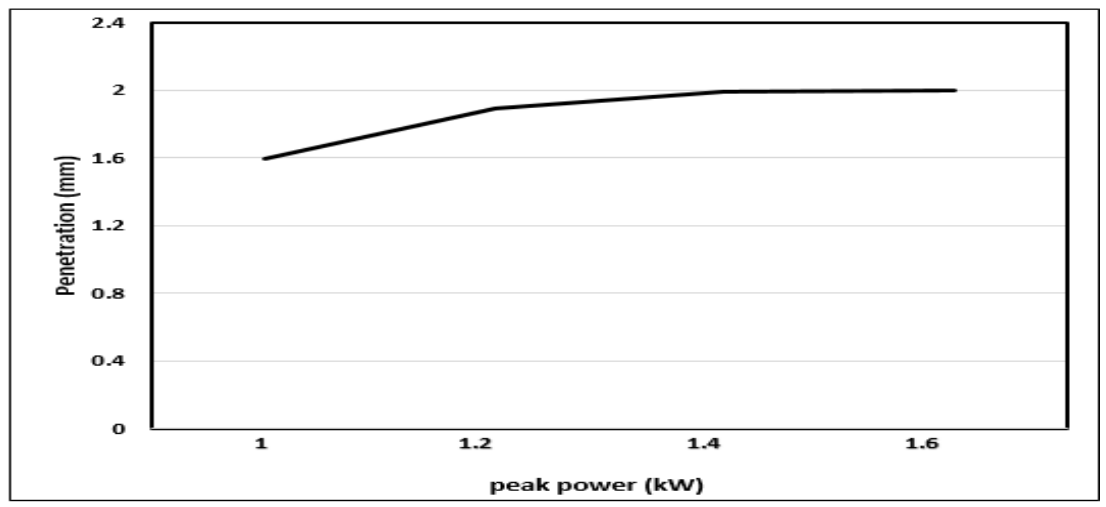

Fig. 6. Relation between peak power and Penetration.

The maximum heat flow direction and the boundary of fusion zone are perpendicular, therefore the grains are likely to grow most rapidly there, leading to columnar grains in the zone of fusion (Fig.7). The zone of weld metal is featured as a regular and narrow shape devoid of defects like shrinkage and solidification. Taken at higher magnification, the best micrographs indicated that the structure that was corresponding consisted of elongated primary ferrite grains.

During welding, the orientation of grain approximately succeeds the direction of the heat flux. Also, a little proportion of austenite was visible, which mainly had precipitated from the boundary of ferrite grain and interior of grain, in finer form. Observed as a faded area on macro-view of welded joint (Fig.7), the narrow heat-affected zone was not corresponding to any important modification of structure on a micro-scale. The noticeable alteration was barely discerned in the high-temperature heat affected zone adjacent to the fusion line, in which the indication of developing decomposition of the austenite phase occurred in an area from the bead of weld [14,25]

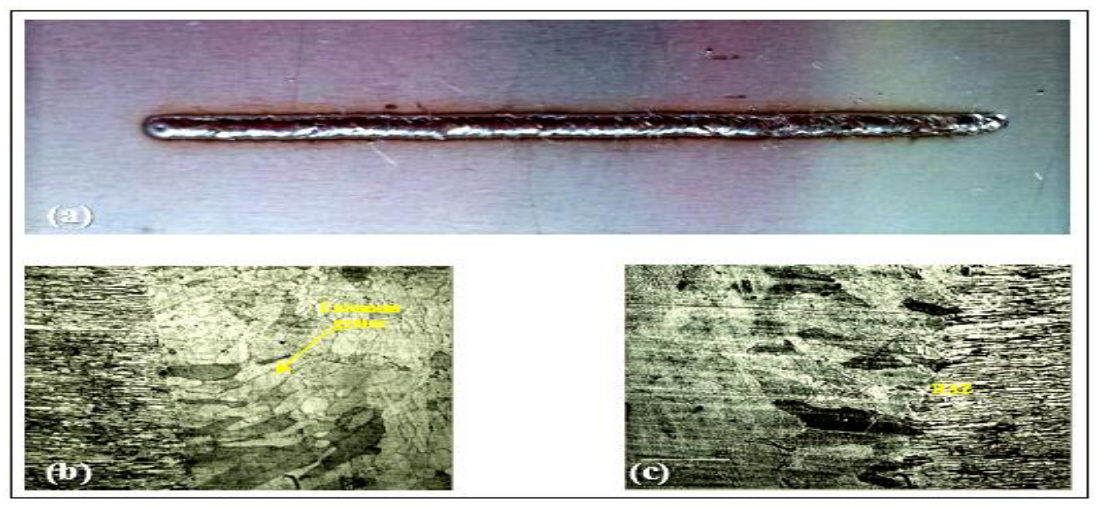

Fig. 7. Macrograph (a) and micrograph (b), (c) of bead-on-plate fiber laser welding of duplex stainless steel. 


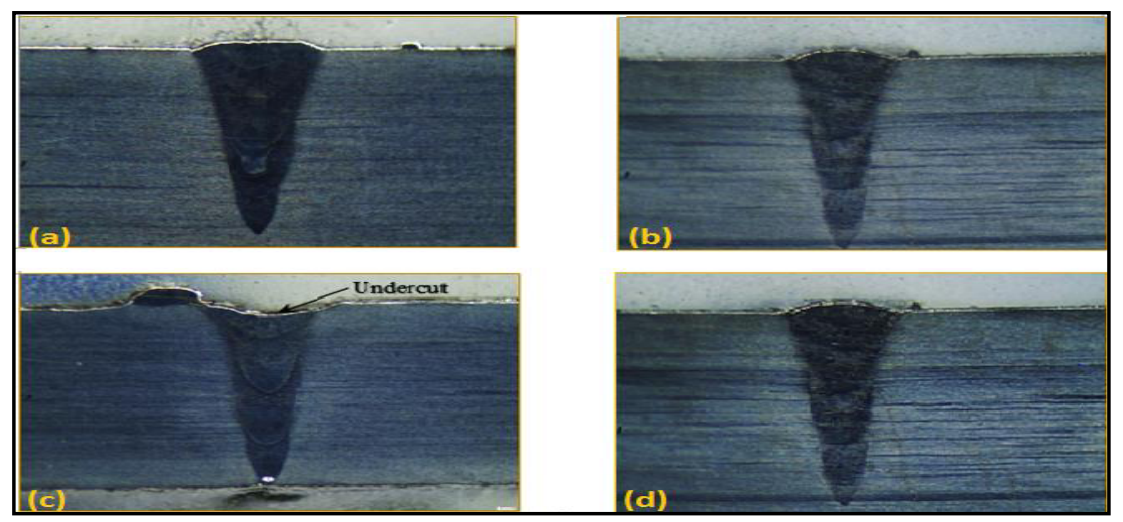

Fig. 8. Effect of different welding speed (a) 0.08 , (b) 0.09 , (c) 0.16 , and (d) $0.11 \mathrm{~m} / \mathrm{min}$ on the depth and width of the weld bead.

\section{Conclusions}

In this research and based on the outcomes accomplished in, the following conclusions can be represented. First of all, the welds produce by the fiber laser parameters highlighted a uniform and thin weld metal zone without any defects like shrinkage and solidification. Also, the structure of weld metal comprised an extended ferrite grains besides a limited measure of austenite, fundamentally place at the border of the grain.

Fiber laser welding resulted in a pronounced reduction in the size of FZ and a weld profile that is acceptable. However, the minimum FZ size produced relied on the input of heat which is a function of LBW parameters.in addition, fiber laser welding is expected to result in an enormous difference in the balance of ferrite-austenite of FZ comparable to the BM due to high cooling rate.

Lastly, hardness profile of duplex stainless steel is affected by the heat input, an increase in the heat input results in the decrease of hardness.

\section{References}

1. M. Yousefieh, M. Shamanian, A. Saatchi, JISR, International, 18(9), 65-69 (2011)

2. W. Steen, K.G. Watkins, J. Mazumder, Springer SBM, (2010)

3. S. Katayama, H. Nagayama, M. Mizutani, Y. Kawahito, WI, 23(10), 744-752 (2009)

4. A.-M. El-Batahgy, A. Tsuboi, , SFC, 8(3), 189-203 (2014)

5. K.A. Chandler, , Elsevier, (2014)

6. J.K.L. Lai, C.H. Shek, K.H. Lo, B. Sci. Publishers, (2012)

7. S. Tavares, V. Terra, J. Pardal, M.C. Fonseca, JMS, 40(1), 145-154 (2005)

8. V.S. Moura, L.D. Lima, J.M. Pardal, A.Y. Kina, R.R.A. Corte, S.S.M. Tavares, MC, 59(8), 1127-1132 (2008)

9. B. Deng, Z. Wang, Y. Jiang, T. Sun, J. Xu, J. Li, Corr Sci, 51(12), 2969-2975 (2009)

10. J. Dobránszky, J. Ginsztler, MSF, Trans Tech Publ, pp 2119-2122 (2007).

11. V. Muthupandi, P.B. Srinivasan, S. Seshadri, S. Sundaresan, Mat. Sci.Eng: A, 358(1), 9-16 (2003)

12. I.F. KoleniČ, D.-I.L. Kovac, D.-I.D. Drimal, WW, 55(5-6), 19-25 (2011)

13. A.H.I. Mourad, A. Khourshid, T. Sharef, Mat. Sci.Eng: A, 549, 105-113 (2012)

14. B.R. Gnanasundaram, M. Natarajan, MT, 48(5), 761-763 (2014)

15. J. Pekkarinen, V. Kujanpää, PP, 5, 517-523 (2010) 
16. A.-M. El-Batahgy, A.-F. Khourshid, T. Sharef, , M Sci App, 2(10), 1443-1451 (2011)

17. M.M.A. Khan, L. Romoli, M. Fiaschi, G. Dini, F. Sarri, J Mat. Proc. Tech., 212(4), 856-867 (2012)

18. W. Duley, Laser processing and analysis of materials, Springer Sci. \& BM (2012)

19. J. Dutta Majumdar, I. Manna, , IMR, 56(5/6), 341-388 (2011)

20. G. Moskvitin, A. Polyakov, E. Birger, WI, 27(7), 572-580 (2013)

21. Z. Zhang, H. Jing, L. Xu, Y. Han, L. Zhao, Mat.\& Des, 109, 670-685 (2016)

22. I.M. Association, T. Stainless, Practical guidelines for the fabrication of duplex stainless steels, 3rd Edition., IMOA, London, UK (2014).

23. F. Mirakhorli, F.M. Ghaini, M. Torkamany, JMEP, 21(10), 2173-2176 (2012)

24. Y. Zhao, Y. Zhang, W. Hu, X. Lai, , Opt.\& Las.En., 50(9), 1267-1273 (2012)

25. V. Amigó, V. Bonache, L. Teruel, A. Vicente, WI, 20(5), 361-366 (2006) 